\title{
MANAGEMENT OF POSTERIOR SEGMENT INTRAOCULAR FOREIGN BODY WITH VITRECTOMY; VISUAL AND ANATOMICAL OUTCOME
}

\author{
Ritesh Kumar Shah ${ }^{1}$, Raghunandan Byanju², Sangeeta Pradhan ${ }^{3}$
}

\begin{abstract}
AIM:

To evaluate the anatomical and visual outcome following removal of intraocular foreign body (IOFB) through pars planavitrectomy.

\section{MATERIAL \& METHODS:}

A retrospective analysis of 11 cases of retained posterior segment foreign body that underwent pars planavitrectomy for removal of foreign body during the period of January 2013 to August 2017 was conducted. Demographics of patients, mechanism and details of injury, Snellen best corrected visual acuity, examination results at presentation and after surgery, any diagnostic imaging and surgical procedure were recorded and analysed.
\end{abstract}

\section{RESULTS:}

Out of eleven eyes of eleven patients (mean age $=25.4 \pm 8.6$, range 2250 years; all male) preoperative retinal detachment and endophthalmitis was seen in $27.3 \%$ and $36.4 \%$ of cases respectively. Eighty-two percent of cases presented within 17 days of sustaining injury. Foreign body size ranged from $2 \mathrm{~mm}$ to $8 \mathrm{~mm}$ and all were magnetic metal. After vitrectomy and removal of foreign body, the number of eyes with vision of hand motion or worse decreased from $72.7 \%$ to $27.3 \%$. Similarly $45.5 \%$ of eyes gained best corrected postoperative visual acuity of better than $6 / 60$. Anatomical success could be achieved in $81.8 \%$ of eyes.

\section{CONCLUSION:}

Anatomical outcome following vitrectomy in eyes with retained posterior segment IOFB in terms of retinal attachment is sufficient; however, visual outcome can be affected by other collateral ocular injuries and their sequelae.

KEY WORDS: posterior segment intra-ocular foreign body, vitrectomy and visual outcome.

1. Ophthalmologist, Bharatpur Eye Hospital, Bharatpur, Chitwan, Nepal.

2. Chief Medical Director, Retina specialist, Bharatpur Eye Hospital, Bharatpur, Chitwan, Nepal.

3. Ophthalmologist, Bharatpur Eye Hospital, Bharatpur, Chitwan, Nepal.

For Correspondence: Dr. Ritesh Kumar Shah MD Ophthalmology Bharatpur Eye Hospital, Bharatpur, Chitwan, Nepal Email:rites_70@hotmail.com 


\section{INTRODUCTION}

Open globe injuries are often associated with retained intraocular foreign body (IOFB). It is seen in $18-41 \%$ of open globe injuries, with majority of cases occurring in young men less than 40 years old ${ }^{1-3}$. IOFB results from a high velocity projectile arising from hammering metal on metal (60-80\%) or power tool or explosives ${ }^{1}$. Ocular injuries with retained IOFB possess a serious threat to vision due to the mechanical damage to intraocular structures, introduction of infection and chemical reaction of the foreign body ${ }^{4}$.Thus, they are often associated with corneal and sclera wound, hyphema, cataract, vitreous hemorrhage, retinal detachment and endophthalmitis ${ }^{5-7}$.

Removal of posterior segment foreign body in pre-vitrectomy era was solely dependent on the use of hand held external electromagnet for magnetic foreign body $(\mathrm{FB})$ and forceps in cases with non-magnetic FB. This technique was highly unpredictable and was associated with iatrogenic trauma to eye and development of proliferative vitreoretinopathy (PVR) changes ${ }^{8}$. Now pars planavitrectomy and removal of FB with magnet or forceps is the preferred and widely practiced approach by many surgeons ${ }^{4,9,10}$.

In this study, we share our experience with vitrectomy and removal of FB in cases with posterior segment IOFB and their visual outcome.

\section{MATERIAL \& METHODS:}

A retrospective review of all the cases of intraocular foreign body of posterior segment from January, 2013 to August, 2017 was done at Bharatpur eye hospital in Bharatpur, Nepal. Eyes having open globe injury (OGI) with retained posterior segment intraocular foreign body (IOFB) who had undergone surgical intervention were included in this study. Surgically induced retained IOFBs such as intraocular lenses were excluded from the current study.

Medical records were reviewed for demographics of patients, mechanism and details of injury, Snellen best corrected visual acuity, examination results at presentation and after surgery, any diagnostic imaging and surgical procedure.

A written informed consent was obtained from all the subjects prior to surgery. A standard 20 gauze three ports pars planavitrectomy with simultaneous pars planalensectomy when considered necessary was performed. IOFB was removed by forceps or an intraocular magnet. Perflu ropropane $(\mathrm{C} 3 \mathrm{~F} 8)$ or silicone oil was used for intraocular tamponade when required. Endolaser photocoagulation of the breaks and $360^{\circ}$ photocoagulation of the retinal periphery was done. Postoperative retinal detachment, partial or total was considered an anatomical failure. Statistical analyses were performed using Statistical Product and Service Solutions (SPSS) software version 20, (SPSS Inc, Chicago, IL, USA).The paired $t$-test and the chi square test were performed for data analysis. A $P$ value less than 0.05 was considered statistically significant.

\section{RESULTS:}

Eleven eyes of 11 patients were included in the study. Demographical data of the patients is shown in Table 1. Age of patients ranged from 22 to 50 years. Duration of interval of injury to presentation ranged from 2 days to 1 year. $82 \%$ of cases presented to the hospital within 17 days of injury. All the patients were operated within 1-3 days of presentation. Mechanism of injury in all these patients was hammering (nail, stone, concrete block, or iron rod).

\begin{tabular}{|l|l|l||}
\hline \multicolumn{2}{|l|}{ Demographics $(\mathrm{n}=11)$} & \multicolumn{2}{l||}{} \\
\hline \hline Mean age & Years Mean \pm SD & $35.4 \pm 8.6$ \\
\hline \hline Gender & Male & 11 \\
\cline { 2 - 3 } & Female & 0 \\
\hline \hline Eye & Right & $8(72.7 \%)$ \\
\cline { 2 - 3 } & Left & $3(27.3 \%)$ \\
\hline Mean interval & Days Mean \pm SD & $66 \pm 132.5$ \\
\hline
\end{tabular}

\section{Table 1: Demographics data}

All the foreign bodies extracted were magnetic metal. Size of the foreign body ranged from $2 \mathrm{~mm}$ to $8 \mathrm{~mm}$ and mean size was $3.1 \mathrm{~mm}$. IOFB characteristics are shown in Table 2.

\begin{tabular}{|l||l||}
\hline IOFB entrance & $54.5 \%$ \\
Cornea & $45.5 \%$ \\
\hline Sclera & \\
Retina & $72.7 \%$ \\
Vitreous & $27.3 \%$ \\
\hline \hline IOFB type & $100 \%$ \\
\hline Metallic & \\
\hline
\end{tabular}

Table 2: IOFB characteristics. 
Co-morbidities are shown in Table 3

\begin{tabular}{|l|l|}
\hline Anterior segment & $6(54.5 \%)$ \\
Corneal wound & $5(45.5 \%)$ \\
Scleral wound & $2(18.2 \%)$ \\
Hyphema & $3(27.3 \%)$ \\
Capopyon & $5(45.5 \%)$ \\
Lens rupture & $2(18.2 \%)$ \\
\hline Posterior segment & $3(27.3 \%)$ \\
Retinal detachment & $4(36.4 \%)$ \\
Endophthalmitis & $2(18.2 \%)$ \\
Vitreous hemorrhage & \\
\hline
\end{tabular}

Table 3. Co-morbidities.

Preoperative retinal detachment (RD) was seen in $3(27.3 \%)$ eyes. In one case attachment surgery was not possible due to severe PVR changes. Endophthalmitis was seen in 4 of 11 eyes $(36.4 \%)$ at presentation. No microbial growth was seen in any of the vitreous samples from eyes with endophthalmitis. Three of 4 eyes with endophthalmitis had postoperative VA better than 6/60 whereas one case developed postoperative RD had VA of light perception.

Anatomical success was achieved in 9 of 11 cases (81.8\%). Out of 2 cases where retina could not be attached, one had FB incarcerated in retina and detachment was associated with high grade proliferative vitreoretinopathy (PVR) changes. Second case was that of endophthalmitis which developed post-operative retinal detachment 4 weeks after removing IOFB.

Visual outcome is shown in Table 4.

\begin{tabular}{|l|l|l|l|l|}
\hline & \multicolumn{2}{|l|}{ VA at presentation } & \multicolumn{2}{l|}{$\begin{array}{l}\text { VA3 months } \\
\text { postoperative }\end{array}$} \\
\hline & Frequency & Percent & Frequency & Percent \\
\hline \hline$</=$ HM & 8 & 72.7 & 3 & 27.3 \\
\hline \hline cf to $\leq 1 / 60$ & 1 & 9.1 & 3 & 27.3 \\
\hline$>1 / 60$ to $\leq 6 / 60$ & 2 & 18.2 & 0 & 0 \\
\hline$>6 / 60$ & 0 & 0 & 5 & 45.5 \\
\hline \hline Total & 11 & 100 & 11 & 100.0 \\
\hline
\end{tabular}

Table 4: Visual outcome

The number of patients with preoperative best corrected visual acuity (BCVA) of hand motion or worse was seen in 8 patients that decreased to 3 in number, three months after surgery. However, one patient lost follow up 4 days after surgery. BCVA improved to more than $6 / 60$ in 5 patients after surgery.

Various causes of postoperative visual impairment were aphakia, epiretinal membrane, retinal detachment with severe PVR changes, corneal scarring, high astigmatism secondary to corneal repair and retinal scarring.

\section{DISCUSSION}

Pars planavitrectomy is the preferred technique for removal of IOFB as it allows management of associated posterior segment injuries. Factors that determine the visual outcome include nature and location of the foreign body, interval between the injury and surgery, initial visual acuity, entrance wound location, preoperative retinal detachment, presence of intraocular hemorrhage, presence of endophthalmitis and the type of surgery.

Injuries at work place when hammering was the cause for IOFB in all the patients in this study. As seen in this study, many studies have also found that retained IOFB was commonly due to work related injuries ${ }^{11,12}$. However bomb blast injury has been reported to be the commonest source of IOFB in some studies ${ }^{13}$.

In our study preoperative retinal detachment was seen in $27.3 \%$ of cases. The rate of retinal detachment associated with IOFB as seen in previous studies ranged from 16 to $47 \%{ }^{14,15,16}$. Postoperative retinal detachment occurred in $18.2 \%$ of eyes. One of these eyes had preoperative total retinal detachment with severe PVR changes and the other had presented with endophthalmitis. Various studies have reported the rate of postoperative retinal detachment ranging from $6.3 \%$ to $36.8 \%{ }^{17,18}$. The number of cases with preoperative endophthalmitis was remarkably high as compared to other studies. The reported incidence was 0 to $13.5 \%{ }^{19}$.

In this study 4 of 11 cases (36.4\%) presented with features suggestive of endophthalmitis. The diagnosis of endophthalmitis was established in these cases based on the clinical signs and B scan ultrasonography. Vitreous sample from none of these eyes demonstrated microbiological growth. Median duration of injury to presentation in eyes with endophthalmitis was 6 days which was less when compared with eyes without endophthalmitis (i.e. 8 days). Hence longer interval between injury and surgery did not appear to be a risk factor for endophthalmitis. In contrast to this Chaudhry et $\mathrm{al}^{7}$ noticed delayed repair of globe and removal of IOFB as the most predictive factor of developing endophthalmitis.

Postoperative BCVA remained unchanged in $27.3 \%$ of cases which was similar to the outcome in a study done in 48 patients 
$(31.9 \%)^{20}$. Remarkable improvement in BCVA was seen in $36.4 \%$ of cases from HM or worse to better than $6 / 60$. We found a final BCVA of $6 / 60$ or better in $45.5 \%$ of eyes and final anatomical success was seen in 9 of 11 patients $(81.9 \%)$.

The limitations of this study include small sample size, retrospective nature of the study and a short follow up of 3 months after surgery. At this time some patients still had treatable complications like aphakia and epiretinal membrane.

\section{CONCLUSION}

In conclusion pars planavitrectomy for foreign body extraction results in a very good anatomical outcome in terms of retinal attachment. Similarly visual outcome although good in most cases, can be affected in others by collateral ocular injuries and their sequelae.

\section{REFERENCES:}

1. Greven CM, Engelbrecht NE, Slusher MM, Nagy SS. Intraocular foreign bodies: management, prognostic factors, and visual outcomes. Ophthalmology. 2000;107:608-612.

2. Roper-Hall MJ. Review of 555 cases of intra-ocular foreign body with special reference to prognosis. Br J Ophthalmol. 1954;38:65-99.

3. Williams DF, Mieler WF, Abrams GW. Intraocular foreign bodies in young people. Retina. 1990;10(Suppl 1):S45-S49.

4. Ahmadieh H, Soheilian M, Sajjadi H, Azarmina M, Abrishami $M$. Vitrectomy in ocular trauma factors influencing final visual outcome. Retina 1993; 13:107-13.

5. Peyman GA, Raichand M, Goldberg MF, Brown S. Vitrectomy in the management of intraocular foreign bodies and their complications. BrJOphthalmol. 1980;64:476-82.

6. Alfaro DV, Roth D, Liggett PE. Posttraumatic endophthalmitis. Causative organisms, treatment, and prevention.Retina. 1994;14:206-11.

7. Chaudhry IA, Shamsi FA, Al-Harthi E, Al-Theeb A, Elzaridi E, Riley FC. Incidence and visual outcome of endophthalmitis associated with intraocular foreign bodies. Graefes Arch Clin. 2008;246:181-6.

8. Francis A, Mieler WF. Management of Intraocular Foreign Bodies of the Posterior Segment, Treatment strategies to maximize anatomical and functional outcomes Retinal Physician, Volume: 13, May 2016, page(s): 26, 28, 30, 31, 5961

9. Bencic G, Vatavuk Z, Mandic Z. Novel approach in the treatment of intravitreal foreign body and traumatic cataract: Three case reports. Croat Med J. 2004;45:283-86.
10. Pavlovic S. Primary intraocular lens implantation during pars planavitrectomy and intraretinal foreign body removal. Retina. 1999;19:430-6.

11. Mocanu C, Badescu S. A morbidity study of intraocular foreign bodies. Oftalmologia1993; 37:25-32.

12. Lai YK, Moussa M. Perforating eye injuries due to intraocular foreign bodies. Med JMalaysia 1992; 47:212-9

13. Jan $S$, Khan $S U$, Karim S, Hussain Z, Khan S, Dawar S, et al. Open globe injuries with intraocular foreign body visual outcome and co-morbidities. Ophthalmology 2010; 8:51-5.

14. Zhang Y, Zhang M, Jiang C, Qiu HY. Intraocular foreign bodies in china:clinical characteristics, prognostic factors, and visual outcomes in 1,421 eyes.Am JOphthalmol. 2011;152:66-73.

15. Erakgun T, Egrilmez S. Prognostic factors in vitrectomy for posteriorsegment intraocular foreign bodies. J Trauma. 2008;64:1034-7.

16. Bai HQ, Yao L, Meng XX, Wang YX, et al. Visual outcome following intraocular foreign bodies: a retrospective review of 5-year clinical experience. Eur JOphthalmol. 2011;21:9810-3.

17. Wickham L, Xing W, Bunce C, Sullivan P. Outcomes of surgery for posterior segment intraocular foreign bodies-a retros pective review of 17 years of clinical experience. Graefes Arch ClinExpOphthalmol. 2006;244:1620-6

18. Yeha S, Colyerb MH, Weichel ED. Current trends in the management of intraocular foreign bodies.Curr OpinOphthalmol. 2008; 19:225-33.

19. Mester V, Kuhn F. Intraocular foreign bodies. OphthalmolClin North Am. 2002; 15:235-42.

20. Falavariani $K G$ et al. Vitrectomy for posterior segment intraocular foreign bodies, visual and anatomical outcomes. Middle East Afr J Ophthalmol 2013; 20: 244-7. 